NASA-CR-205254

\title{
Seasonal variation of mass transport across the tropopause
}

\author{
Christof Appenzeller and James R. Holton \\ Department of Atmospheric Sciences, University of Washington, Seattle
}

\author{
Karen H. Rosenlof \\ NOAA, University of Colorado, Boulder
}

\begin{abstract}
The annual cycle of the net mass transport across the extratropical tropopause is examined. Contributions from both the global-scale meridional circulation and the mass variation of the lowermost stratosphere are included. For the northern hemisphere the mass of the lowermost stratosphere has a distinct annual cycle, whereas for the southern hemisphere, the corresponding variation is weak. The net mass transport across the tropopause in the northern hemisphere has a maximum in late spring and a distinct minimum in autumn. This variation and its magnitude compare well with older estimates based on representative ${ }^{90} \mathrm{Sr}$ mixing ratios. For the southern hemisphere the seasonal cycle of the net mass transport is weaker and follows roughly the annual variation of the net mass flux across a nearby isentropic surface.
\end{abstract}

\section{Introduction}

Soon after the start of nuclear bomb testing in the stratosphere in the late $1950 \mathrm{~s}$ it was found that in the northern hemisphere the near surface value of radioactive debris showed a spring maximum and an autumn minimum [e.g., Fry et al., 1960]. It was argued [e.g., Staley, 1962] that this seasonal variation in radioactivity could be linked to a seasonal cycle in stratosphere-troposphere exchange (STE). Detailed case studies supported this idea [e.g., Danielsen, 1968] and indicated that upper level baroclinic events, such as tropopause folds, are important for mass exchange. Early studies of the seasonal variation of near-tropopause cyclogenesis [Mahlman, 1969] and more recent studies of the frequency of cutoff lows [Price and Vaughan, 1992] and tropopause folds [Beekmann et al. 1996] however showed no preferred occurrence in the spring season. This suggests that other factors than the number of events must be important for producing the apparent spring maximum and autumn minimum in exchange.

In a recent review, Holton et al. [1995] emphasized the globalscale aspects of exchange. They argued that wave-induced zonal forces in the extratropical stratosphere induce a globalscale meridional circulation in which mass is pulled upward and poleward in the tropics and pushed downward in the extratropics. This global-scale meridional circulation, which must be accompanied by radiative heating and cooling, is often referred to as the diabatic circulation [Brewer, 1949: Dobson, 1956]; it shows a clear seasonal cycle in both hemispheres [Rosenlof and Holton, 1993; Rosenlof, 1995]. The maximum downward mass flux across a control surface that lies in the lower stratosphere (e.g., at 100 or $70 \mathrm{hPa}$ ) occurs, however, during the winter and not in late spring.

To understand mass and tracer transport into and out of the middle stratosphere the replacement of the tropopause by a

Copyright 1996 by the American Geophysical Union.

Paper number $96 \mathrm{JD} 00821$.

0148-0227/96/96JD-00821\$09.00 more convenient isobaric or isentropic control surface located in the lower stratosphere is useful. However, for some purposes the mass transport across the actual tropopause is required. The net downward mass fluxes across the extratropical tropopause and across an isobaric or isentropic control surface that nearly coincides with the tropopause in the tropics should be equal for a sufficiently long time average [Holton et al., 1995]. Such equality will not hold on seasonal or shorter timescales since the amount of mass in the layer between the extratropical tropopause and an isobaric or isentropic surface coinciding with the tropical tropopause may vary with time.

It has long been recognized that stratospheric mass variations due to seasonal tropopause height variations can contribute to stratospheric tropospheric air exchange [Staley, 1962; Reiter, 1975; Robinson, 1980; Murgatroyd and O'Neill, 1980]. Because of the lack of global tropopause analyses the globalscale effects of these variations have only been roughly estimated. In this paper the contributions of the seasonal variations of the mass of the lowermost stratosphere and of the global-scale meridional circulation in the stratosphere to the variations in net mass transport across the extratropical tropopause will be explored.

\section{Model for Net Mass Transport}

The simple model used is shown in Figure 1. The shaded region corresponds to the "lowermost stratosphere," also referred to as the stratospheric middle world [Hoskins, 1991; Holton et al., 1995]. In this region mass can be exchanged with the troposphere along isentropic surfaces (dashed-dotted curves). It is separated by a potential vorticity surface (bottom solid curve) from the troposphere and by an isentropic surface (top solid curve) from the overworld, the region of the stratosphere where mass can only be exchanged by crossing isentropic surfaces. The global-scale meridional circulation (open arrows) supports a mass flow $\left(F_{\text {in }}\right)$ directed into the lowermost stratosphere across the upper boundary. By mass continuity 


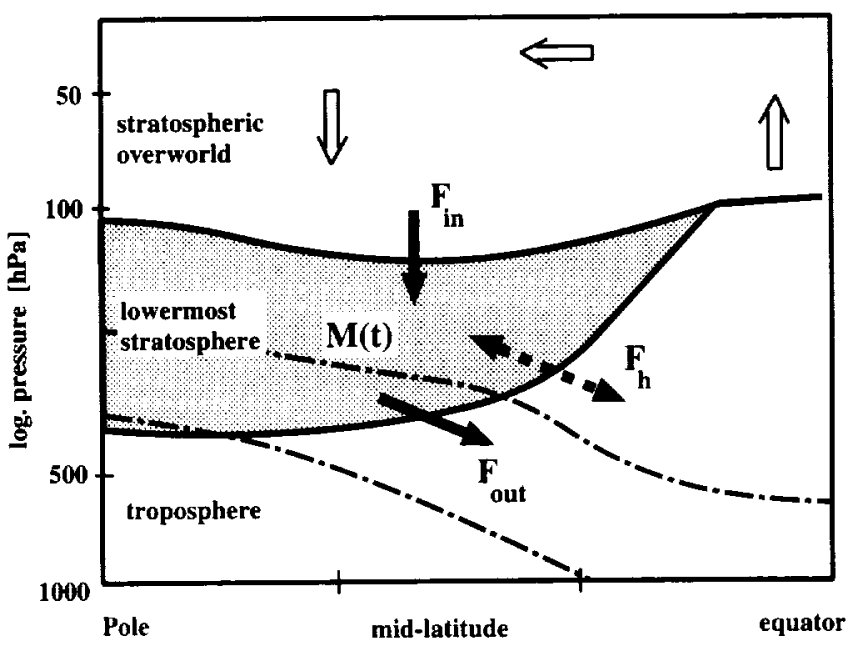

Figure 1. The simple hemispheric net mass transport model. See text for details.

the flow out of the lowermost stratosphere into the troposphere $\left(F_{\text {out }}\right)$ is simply the difference between the inflow from the overworld and the rate of increase of mass $(M)$ of the lowermost stratosphere:

$$
F_{\text {out }}(t)=\frac{\mathrm{d}}{\mathrm{dt}} M+F_{\text {in }}(t)
$$

where $F_{\text {in }}$ and $F_{\text {out }}$ are both defined to be negative for downward directed mass fluxes.

In this model any two-way transport $\left(F_{h}\right)$ between the tropophere and the lowermost stratosphere that is characterized by a zero net mass transport across the tropopause is not included. Assuming that $M$ and $F_{\text {in }}$ can be calculated from "observed" data, equation (1) provides a simple way to estimate the net mass flux $F_{\text {out }}$ across the tropopause, without doing any flux calculation at the tropopause itself.

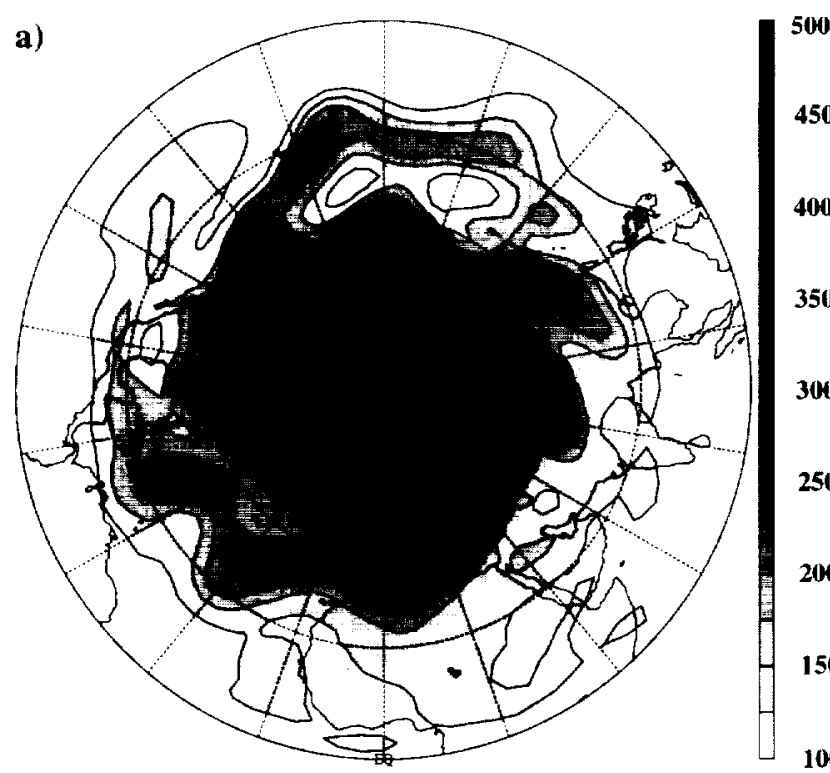

\section{Mass of Lowermost stratosphere}

The mass of the lowermost stratosphere is given by

$$
M=\int_{0}^{2 \pi} \int_{-\pi / 2}^{\pi / 2} \int_{P_{1}}^{P_{2}}-\frac{1}{g} d p \cos \phi d \phi d \lambda
$$

where $g$ is gravity, $\lambda$ is longitude, $\phi$ is latitude, $p$ is pressure, and $P_{1}(\lambda, \phi)$ and $P_{2}(\lambda, \phi)$ represent the pressures on the lower and upper boundary surfaces, respectively. The former is taken to be the 2 PVU potential vorticity surface $\left(1\right.$ PVU $=10^{-6} \mathrm{~K} \mathrm{~m}^{2}$ $\mathrm{s}^{-1} \mathrm{~kg}^{-1}$ ), while the latter is taken to be the $\theta=380 \mathrm{~K}$ isentrope [Hoskins, 1991; Reid and Gage, 1981; Hoskins et al., 1985; Holton, et al., 1995]. The global tropopause is therefore defined by a combination of a potential vorticity and a potential temperature surface. The sensitivity of the calculation to the chosen PV and $\theta$ value is discussed below.

The atmosphere's PV and $\theta$ structure was calculated for two calendar years 1992 and 1993 from daily (00:00 UT) global stratospheric analyses prepared by the United Kingdom Meteorological Office (UKMO) for the Upper Atmosphere Research Satellite (UARS) project [Swinbank and O'Neill, 1994]. Horizontal winds, geopotential heights, and temperature are provided with a horizontal resolution of $2.5^{\circ}$ latitude by $3.75^{\circ}$ longitude, and vertical resolution $-50 \mathrm{hPa}$ in the lowermost stratosphere.

According to equation (2) any variation of the mass of the lowermost stratosphere is linked to a net variation of the pressure distribution on the tropopause or the $380 \mathrm{~K}$ surface. An example of the instantaneous pressure distribution for both surfaces is given in Figure 2. For both charts the same contour interval of $25 \mathrm{hPa}$ is used. Pressure variations on the isentropic surface are relatively small and nearly zonally symmetric; pressure variations on the tropopause are large and have strong deviations from zonal symmetry. The latter are linked to baroclinic developments and subsynoptic scale

Figure 2. Instantaneous view of the pressure distribution on the northern hemisphere tropopause (a) and $380 \mathrm{~K}$ isentrope (b). Contour interval is $25 \mathrm{hPa}$ for both panels, day number 248 of year 1993.

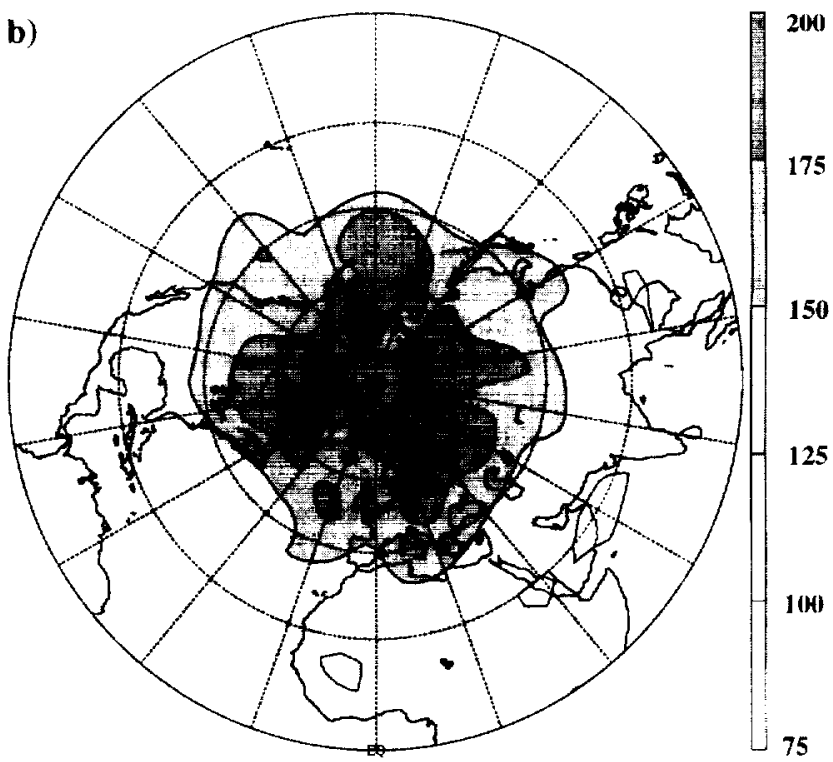




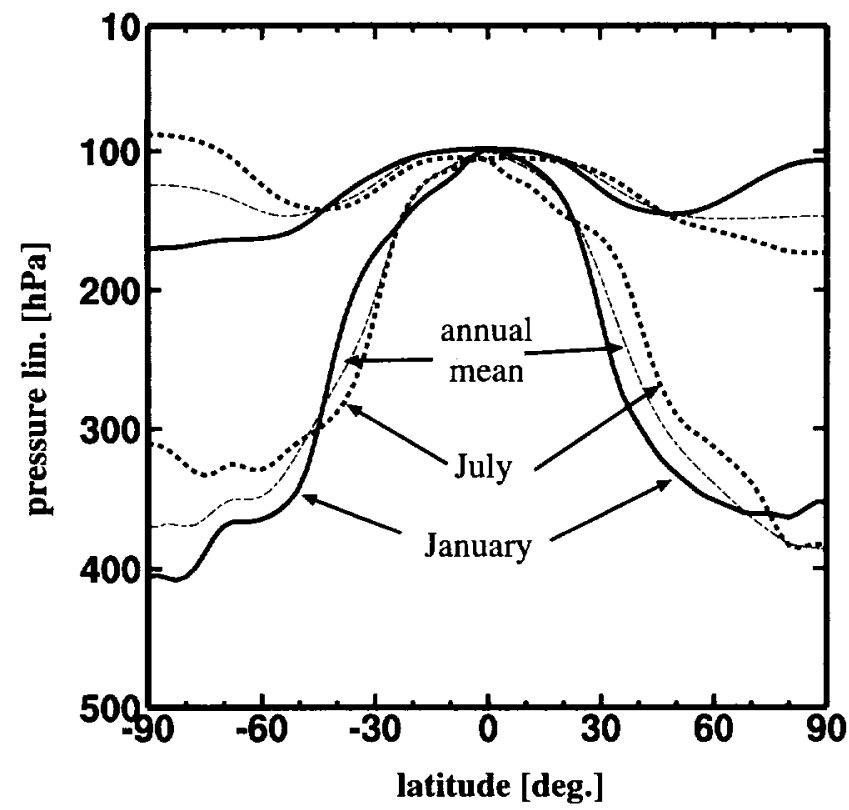

Figure 3. Zonal mean position of the upper and lower boundaries of the lowermost stratosphere for January (solid) and July (dashed) and annual mean (thin long dash). Data are averaged in pressure coordinates and the monthly mean is based on zonal mean daily data for the year 1993.

disturbances, such as cutoff systems and stratospheric intruions [e.g., Hoskins et al., 1985; Appenzeller et al., 1996].

The monthly mean positions of the tropopause and the $380 \mathrm{~K}$ isentrope based on zonal mean daily data are shown in Figure 3 for January and July 1993. In the tropical region the pressure of the $380 \mathrm{~K}$ isentrope appears to be relatively constant with a typical value around $100 \mathrm{hPa}$ and an annual variation of less than $10 \mathrm{hPa}$ (Figure 4a). In the extratropical regions the mean height of the $380 \mathrm{~K}$ surface is for both hemispheres at a maximum in winter and at a minimum in the summer season. This up and down oscillation is consistent with the seasonal variation in the strength of the stratospheric polar vortex. The relative amplitude (Figure 4a) of the oscillation is slightly stronger for the southern hemisphere than for the northern hemisphere, but the overall pattern is comparable.

In the northern hemisphere the tropopause moves upward and poleward during the transition from winter to summer (Figure 3, Figure 4b). In the southern hemisphere a similar shift in the mean position of the tropopause occurs only between $30^{\circ} \mathrm{S}$ and $40^{\circ} \mathrm{S}$. In more poleward southern latitudes the tropopause moves downward and equatorward during the transition from winter to summer. Thus the seasonal cycle in the southern hemisphere tropopause pressure is a "seesaw" oscillation in which a relatively high tropopause in southern subtropical regions is accompanied by a relatively low tropopause in poleward latitudes and vice versa (Figure 4b). Note that at any given time or location the position of the tropopause may differ substantially from the seasonal meridional mean. To incorporate this variability and to avoid any bias due to the averaging procedure, the mass variation of the stratospheric middle world was calculated from equation (2) using daily global data

The calculated mass of the lowermost stratosphere has a distinct seasonal cycle (Figure 5a). For the northern hemisphere a maximum occurs in midwinter and a minimum in late summer, whereas the corresponding seasonal variation for the southern hemisphere is much weaker in amplitude. Some higher frequency variations were also found. For the northern hemisphere their amplitudes are an order of magnitude smaller than the amplitude of the annual variation.

The mass of the stratospheric overworld (Figure 5b) also shows a seasonal cycle. In this case the amplitudes of the cycles in the two hemispheres are comparable, and the phases
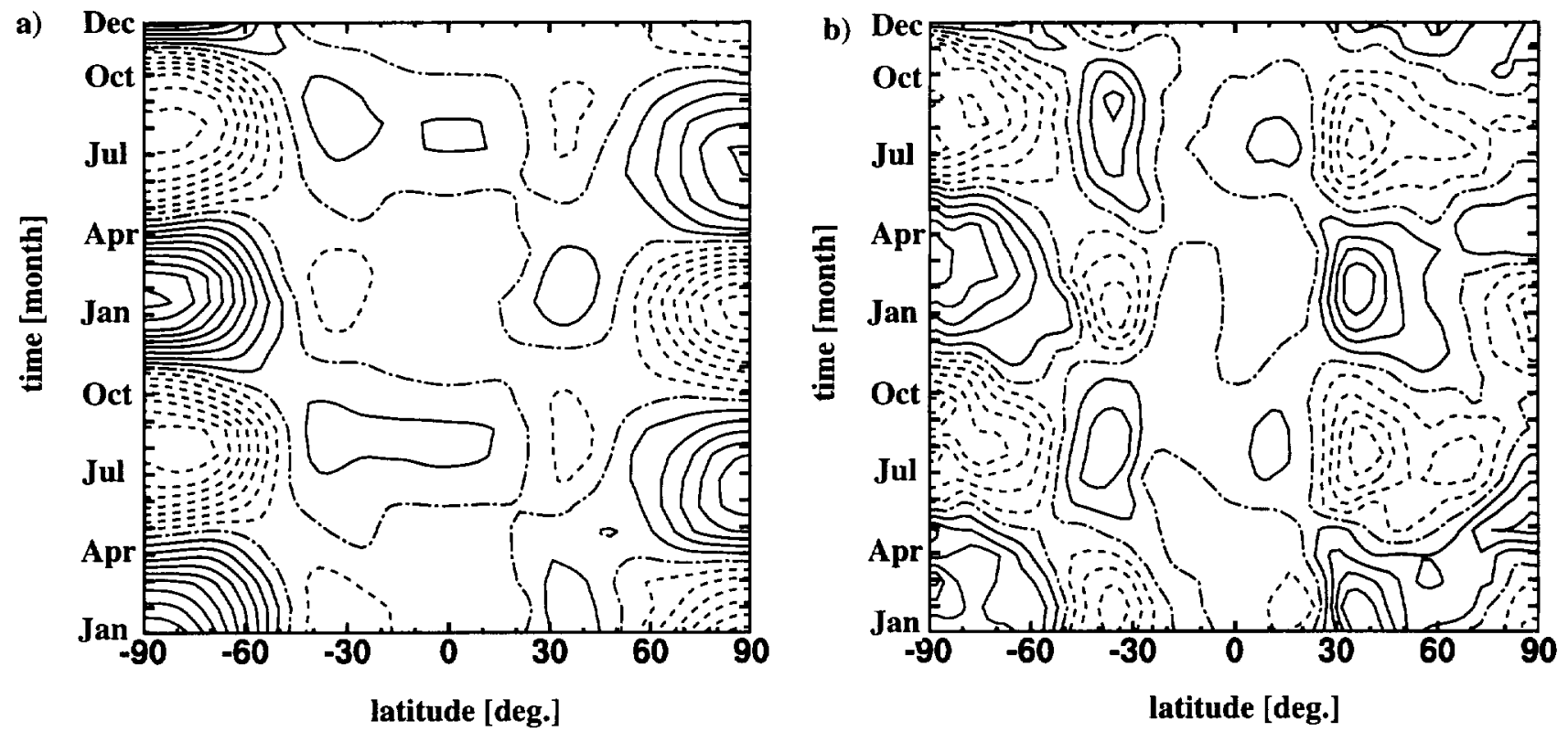

Figure 4. Annual variation of the zonal mean relative pressure on the $380 \mathrm{~K}$ isentrope (a) and the tropopause (b) for the two years 1992 and 1993. The pressure is given relative to the annual zonal mean (as defined in Figure 3) with a contour interval of (a) $5 \mathrm{hPa}$ and (b) $10 \mathrm{hPa}$, negative values dashed, zero line is dashed-dotted. 

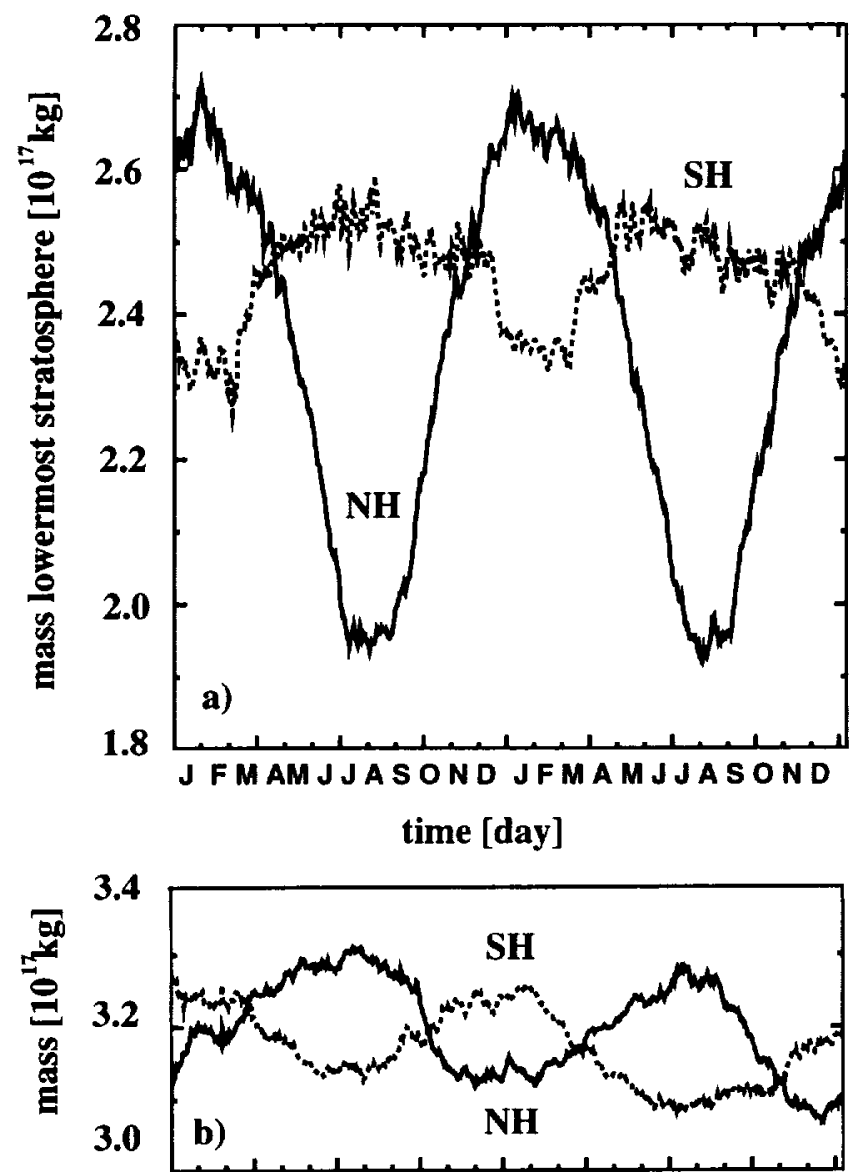

J F M AM JJASOND JFMAM J JASOND time [day]

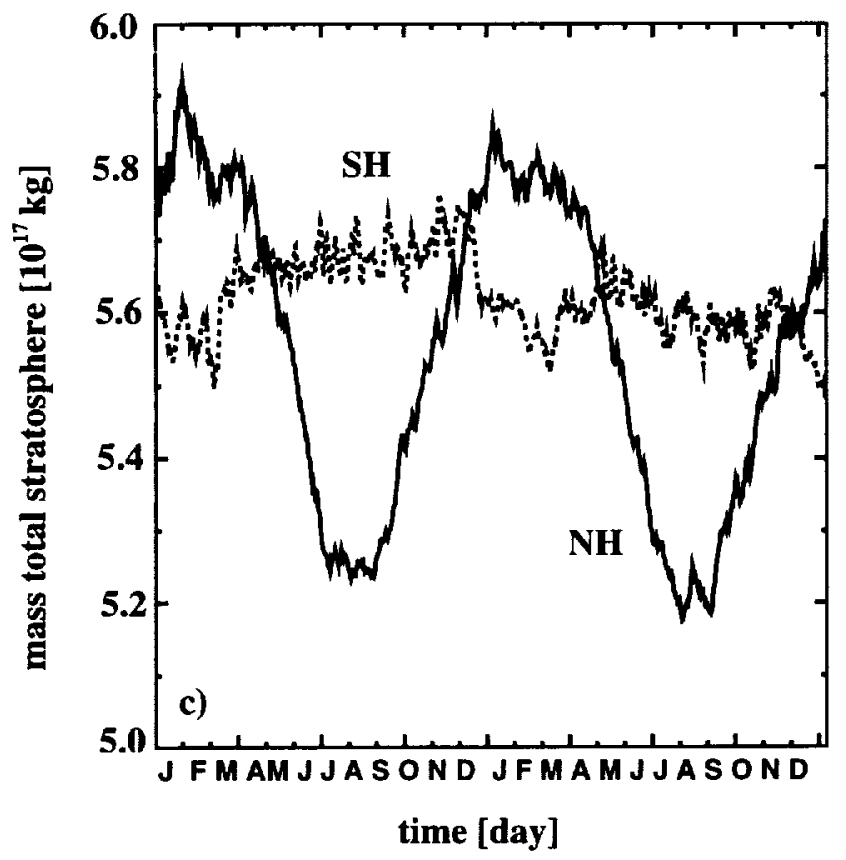

Figure 5. Annual variation of the mass $\left(10^{17} \mathrm{~kg}\right)$ for various subregions of the stratosphere for the two years 1992 and 1993. Plain lines for the northern hemisphere (NH) and dashed lines for the southern hemisphere $(\mathrm{SH})$. (a) Lowermost stratosphere. (b) Stratospheric overworld. (c) Total stratosphere. are opposite to those of the lowermost stratosphere, consistent with the observed up and down oscillation of the $380 \mathrm{~K}$ surface (Figure 3 and 4a). The global stratospheric overworld experienced a weak mass loss of $\sim 1.5 \%$ during the calendar year 1992 and 1993, as was also noted in a recent analysis by Yang and Tung [1996]

Combining Figures $5 \mathrm{a}$ with $5 \mathrm{~b}$ results in the mass variation of the total stratosphere (Figure 5c). For the northern hemisphere this closely follows the variation of the mass of the lowermost stratosphere, which implies that the latter is mainly linked to the seasonal variation of the mean position of the tropopause. For the southern hemisphere the seasonal cycle of the total stratospheric mass is very weak. This is consistent with the seesaw nature of the tropopause pressure oscillations and suggests that the stratospheric air mass is shifted from low latitudes to more poleward latitudes and vice versa without changing the hemispheric averaged tropopause height. The pronounced asymmetry between the two hemispheres that we have found in the annual cycle in total stratospheric mass stands in contradiction to earlier studies that attributed the seasonal mass variation to a mass shift between the two hemispheres [Reiter, 1975] or suggested only a slightly weaker seasonal variation for the southern hemisphere [Murgatroyd and O'Neill, 1980].

The montly mean contribution to $F_{\text {out }}$ due to mass changes of the lowermost stratosphere as given by $d M / d t$ in equation (1) was calculated on the basis of monthly averages of the daily mass values. For the northern hemisphere a maximum downward flux (negative $d M / d t$ ) occurred in late spring (Figure 6), whereas the seasonal cycle for the southern hemisphere is less distinct. Also shown are similar calculations using different definitions for the tropopause and the upper

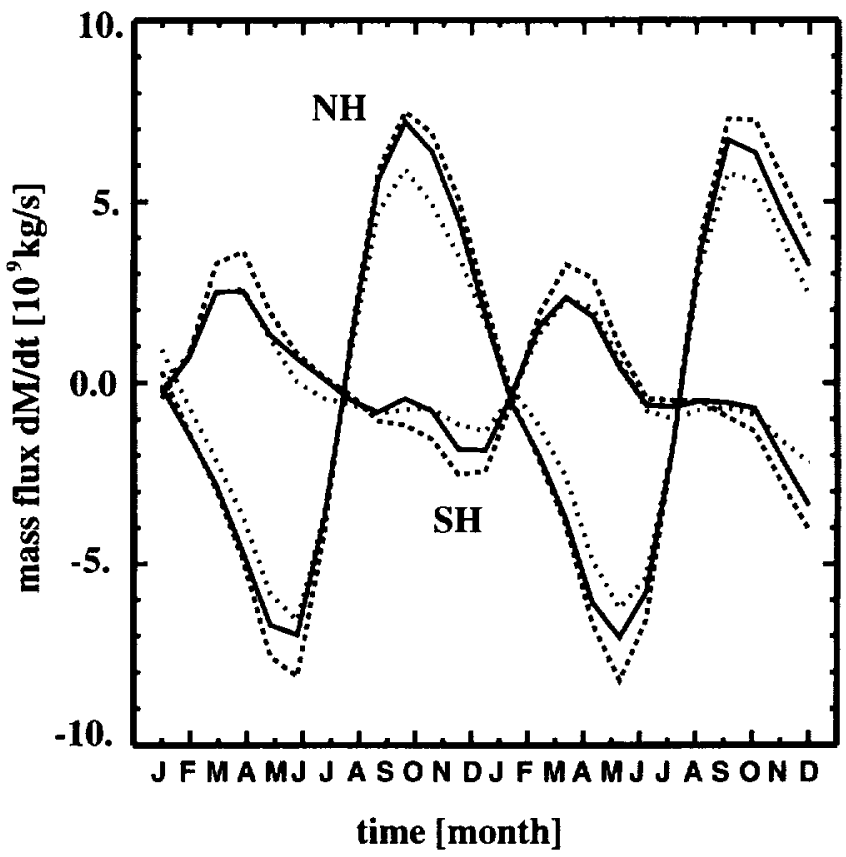

Figure 6. Annual variation of the net mass flux across the tropopause due to the mass variation of the lowermost stratosphere alone, using various definitions of the boundaries for the two years 1992 and 1993. Solid curve, 2 PVU and $380 \mathrm{~K}$; dotted curve, 3 PVU and $380 \mathrm{~K}$; and dashed curve, 2 PVU and $370 \mathrm{~K}$. (Values are given in $10^{9} \mathrm{~kg} \mathrm{~s}^{-1}$; negative values denote mass flux out of lowermost stratosphere.) 
boundary of the lowermost stratosphere. Although the actual total mass values differ, the mass fluxes show only a very weak sensitivity to the choice of control surfaces. This indicates that the above described seasonal variations and their asymmetry between the two hemispheres are quite robust and should also be found using higher-resolution data.

In the northern hemisphere the annual mass variation is $\sim 0.6 \times 10^{17} \mathrm{~kg}$ for the total stratosphere (i.e., $\sim 10 \%$ of the mass of the stratosphere) and $\sim 0.75 \times 10^{17} \mathrm{~kg}$ for the lowermost stratosphere (i.e., $-30 \%$ of the mass of the lowermost stratosphere). The mass variation of the total stratosphere can be used to estimate the minimal annual mass transport across the tropopause. The value given above is of the same order of magnitude as suggested in earlier studies and is about $60 \%$ of that found by Robinson [1980], who used a crude estimate based on the jet displacement alone.

\section{Mass Transport Across Upper Boundary}

To calculate the mass flux $F_{\text {in }}$ across the upper boundary of the lowermost stratosphere, the mass flux across the $380 \mathrm{~K}$ isentrope due to the global-scale meridional circulation was estimated. In isentropic coordinates the vertical velocity is directly given by the net diabatic heating rate $Q$. The zonal mean mass flux rate can then be approximated by [Tung, 1982; Pawson and Harwood, 1989]

$$
F^{\theta} \approx \cos (\phi) \bar{\sigma} \bar{Q}
$$

with

$$
\bar{\sigma}=-\frac{1}{g}\left(\frac{\overline{\partial p}}{\partial \theta}\right)
$$

representing the zonal mean of the density in isentropic coordinates. The monthly averaged net diabatic heating rates $\bar{Q}$ were calculated from the radiative algorithm of Olaguer et al. [1992] with UARS-based constituent measurements and UKMO temperatures as input. The ozone measurements were taken from the Microwave Limb Sounder (MLS), whereas water vapor and methane measurements were from the Halogen Occultation Experiment (HALOE), except for the year 1992 when $\mathrm{H}_{2} \mathrm{O}$ was taken from MLS. At lower pressure levels, climatological values were used. The heating rates were calculated on pressure levels and were corrected for mass imbalances to assure that the net vertical mass flux across a pressure surface is zero [Rosenlof, 1995; Shine, 1989; Solomon et al., 1986]. The mass fluxes calculated from equation (3) using corrected heating rates are nearly equivalent to the mass fluxes obtained using radiatively derived transformed Eulerian mean (TEM) velocities, such as those of Rosenlof [1995], when the latter are interpolated onto isentropic surfaces, and correction is made for the temporal variation of the zonal mean pressure on the isentropic surface (see Appendix).

For the northern hemisphere the extratropical net downward mass flux $\left(F_{\mathrm{in}}\right)$ across the $380 \mathrm{~K}$ surface has a maximum in midwinter and a minimum in late spring to early summer (Figure 7a, plain thick curve). This variation is consistent with the idea that the annual cycle in zonal momentum forcing in the stratosphere controls the downward mass flux into the lowermost stratosphere [Rosenlof, 1995; Holton et al., 1995].

The amplitude of the seasonal cycle of $F_{\text {in }}$ is much weaker when evaluated on an isentropic surface than when evaluated on an isobaric surface with the same annual mean net mass flux. In the southern hemisphere the amplitude evaluated on an isentropic surface is much closer to that evaluated on an isobaric surface (Figure 7, dashed curves). In both hemispheres the phase of the annual cycle in cross-isentropic flux leads that of the cross-isobaric flux by roughly 1 month. The corresponding tropical net upward mass flux across the $380 \mathrm{~K}$ sur-
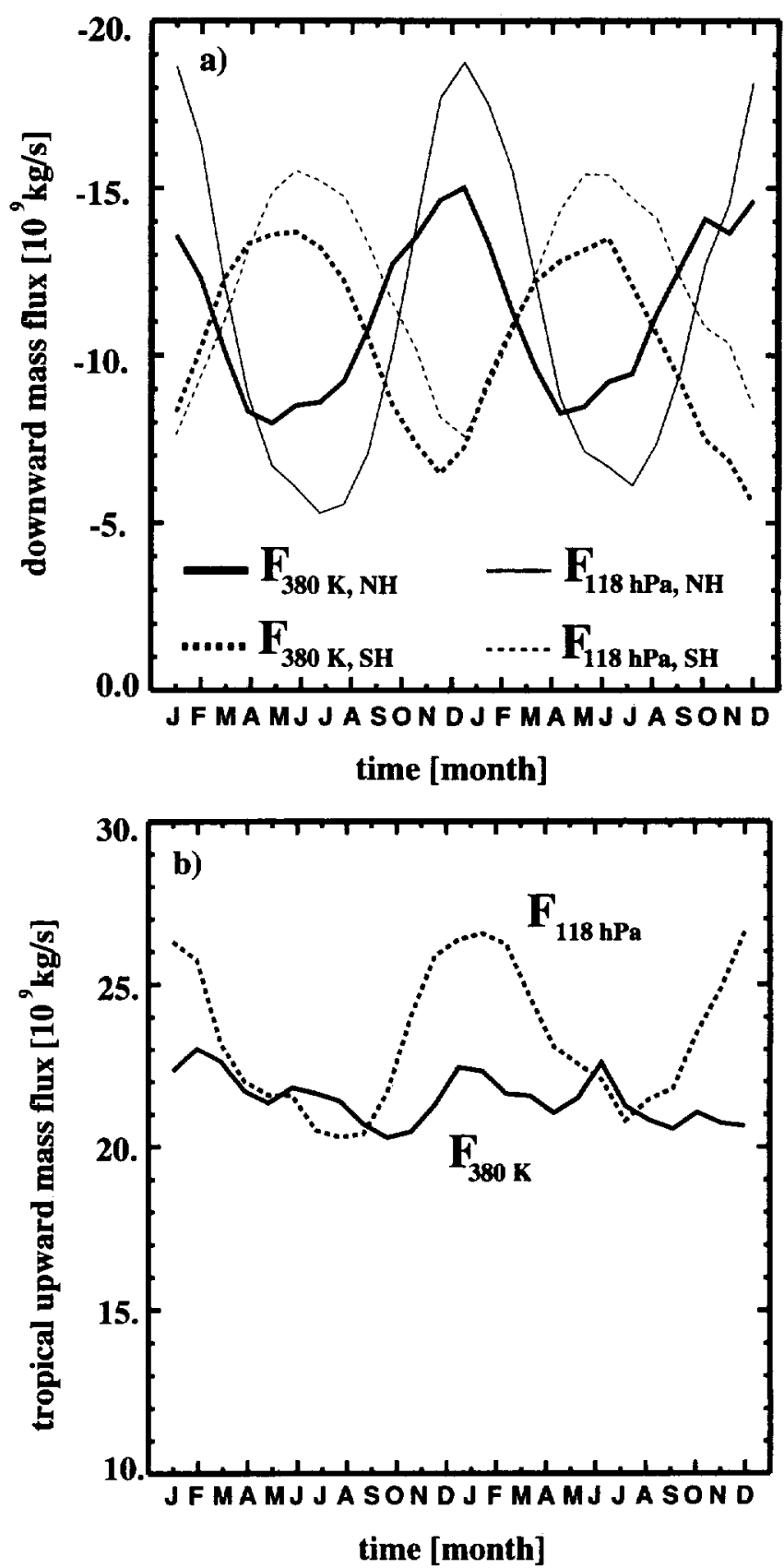

Figure 7. (a) Annual variation of the extratropical net downward mass transport across the $380 \mathrm{~K}$ isentropic surface ( $F_{380}$, thick curves; plain for $\mathrm{NH}$ and dashed for $\mathrm{SH}$ ) and the 118-hPa pressure surface ( $F_{118}$, thin curves; plain for NH and dashed for $\mathrm{SH}$ ) for the two years 1992 and 1993. (b) Same as Figure $7 \mathrm{a}$ but for the tropical net upward mass transport (thick plain across $380 \mathrm{~K}$, thick dashed across $118 \mathrm{hPa}$ ). (Values are given in $10^{9} \mathrm{~kg} \mathrm{~s}^{-1}$; negative values denote downward mass flux.) 
face is shown in Figure $7 \mathrm{~b}$ (solid curve). It has a negligible seasonal cycle in comparison to the one across a pressure surface (dashed curve).

The total annual mean net downward mass fluxes are summarized in Table 1. It is important to bear in mind that these estimates are subject to substantial uncertainties. In the lower stratosphere the net radiative heating rates are a small residual of several large terms and there exists no physically based method to correct the heating rates to achieve global mass balance [Shine, 1989]. An estimate of the uncertainty in the corresponding mass flux rates can be gained by comparing the annual mean net downward mass flux as given in Table 1 with the one calculated in a recent study by Yang and Tung [1996]. They used a slightly different version of the same radiative transfer code [Olaguer et al., 1992] together with a twodimensional isentropic model in assimilation mode to estimate 5-day-averaged mass fluxes across a $385 \mathrm{~K}$ surface. For the northern hemisphere their annual averaged downward mass flux is $-20 \%$ lower than the one calculated here. For the southern hemisphere the difference is $-50 \%$ (Table 1 ). The net mass flux calculated here was also sensitive to the $\theta$ surface selected $(40 \%$ higher at $370 \mathrm{~K}$ and $25 \%$ smaller at $390 \mathrm{~K}$ ). However, the amplitude of the seasonal variation was comparable.

\section{Mass Transport Across the Tropopause}

Substituting $F_{\text {in }}$ and $d M / d t$ in equation (1) yields a simple estimate of the net mass transport $F_{\text {out }}$ across the tropopause. In the northern hemisphere this transport has a distinct seasonal cycle (solid curve in Figure 8a) with a maximum in late spring and a secondary maximum in midwinter. A distinct minimum occurs during autumn. Compared to the mass flux across a $380 \mathrm{~K}$ surface (thin dashed curve in Figure 8), the annual amplitude variation is stronger and the maximum occurs with a phase lag of approximately 5 months. For the southern hemisphere (Figure $8 \mathrm{~b}$ ) the seasonal cycle was much weaker. The mass transport has a maximum in midwinter and is dominated by the mass flux across the $380 \mathrm{~K}$ surface.

\section{Conclusion}

The global-scale meridional circulation and the mass variation of the stratosphere have been analyzed to estimate the net mass transport across the tropopause. The mass calculations and the tropopause analyses were based on the atmosphere's potential temperature and potential vorticity

Table 1. Total Annual Downward Mass Flux Across the 380 and $385 \mathrm{~K}$ Isentropic Surface in Units of $10^{17} \mathrm{~kg} /$ year

\begin{tabular}{lccc}
\hline & $380 \mathrm{~K}$ & $385 \mathrm{~K}$ & Y\&T385 K \\
\hline Northern hemisphere & 3.5 & 3.0 & 2.4 \\
Southern hemisphere & 3.3 & 2.8 & 1.4 \\
\hline
\end{tabular}

The values represent averages over two years (1992 - 1993). The values in column 3 are taken from Yang and Tung [1996] and are averaged over 3 years (1992 - 1994). structure, using assimilated UKMO analysis data. In the northern hemisphere the annual zonal mean changes of the tropopause height are linked to a net mass variation of the lowermost stratosphere. The mass flux due to this variation substantially contributes to the net mass flux across the tropopause and has a maximum in late spring and a minimum in early autumn. For the southern hemisphere the corresponding annual variation is weak, even though the mean position of the tropopause shows a seasonal variation. The
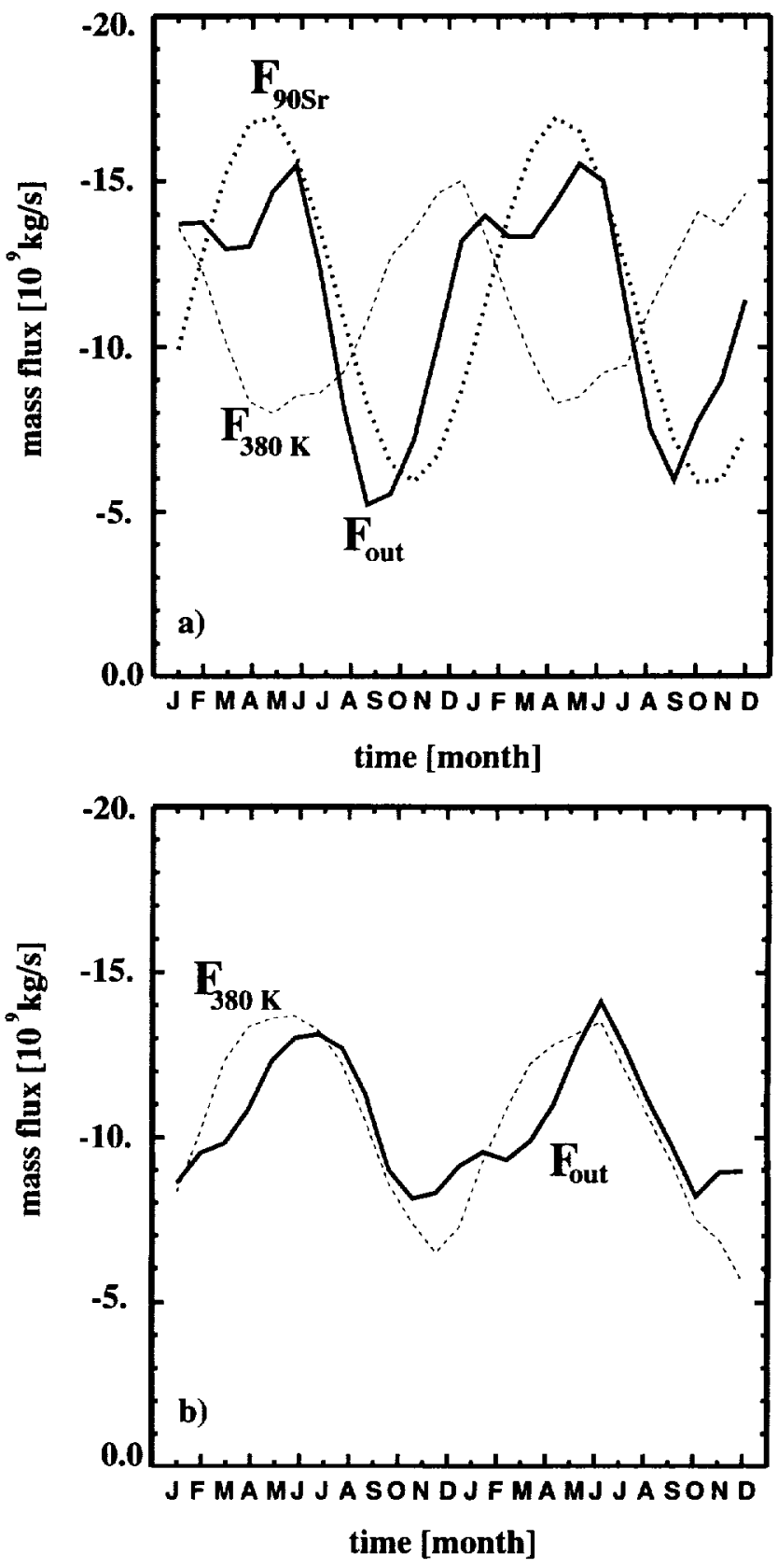

Figure 8. Annual variation of the net downward mass transport across the extratropical tropopause ( $F_{\text {out }}$, thick plain curve), the $380 \mathrm{~K}$ isentropic surface $\left(F_{380}\right.$, thin dashed curve), and mass flux according to ${ }^{90} \mathrm{Sr}$ measurements $\left(F_{90 \mathrm{Sr}}\right.$, dotted line, see text). Shown are the two years 1992 and 1993. (a) Northern hemisphere. (b) Southern hemisphere. (Values are given in $10^{9} \mathrm{~kg} \mathrm{~s}^{-1}$; negative values denote downward mass flux.) 
global scale meridional circulation was approximated by radiatively derived residual velocities, which were calculated based on UARS constituent measurements. The maximum downward mass flux across the upper boundary of the lowermost stratosphere (the $380 \mathrm{~K}$ isentrope) occurs during the winter season, and the minimum flux occurs in early summer. This cycle has a similar phase but weaker amplitude than the annual cycle in the downward mass flux computed for a nearby pressure surface.

According to our simple model shown in Figure 1 it is the combined effects of the seasonal variation of the global-scale meridional circulation and the seasonal variation of the mass of the lowermost stratosphere that determine the net mass transport across the tropopause into the troposphere. For the northern hemisphere this flux shows a late-spring maximum and an autumn minimum. In the southern hemisphere the corresponding annual variation is dominated by the mass flux across the upper boundary of the lowermost stratosphere. The annual variation and its magnitude compare well (Figure 8a) with a northern hemisphere estimate based on representative ${ }^{90} \mathrm{Sr}$ mixing ratios [Danielsen and Mohnen, 1977, equation (1)]. The mass transport cannot be directly interpreted in terms of tracer fluxes; but it can be anticipated that tracer inputs into the troposphere will be strongly correlated with the observed variations in the net mass transport.

\section{Appendix}

The following derivation shows that the zonal mean mass flux rate across an isentropic surface as given in equation (3) is closely related to the mass flux computed from radiatively derived residual velocities (i.e., transformed Eulerian-mean (TEM) velocities [Andrews and McIntyre, 1976; Andrews et al., 1987]). By using the mass streamfunction $\psi$ defined as [Rosenlof and Holton, 1995; Rosenlof, 1995$]$

$$
\begin{aligned}
& \frac{\partial}{\partial z} \psi=-\cos (\phi) \rho_{0} \bar{v}^{*} \\
& \frac{\partial}{\partial y} \psi=\cos (\phi) \rho_{0} \bar{w}^{*}
\end{aligned}
$$

the approximate TEM thermodynamic equation

$$
\frac{\partial \bar{\theta}}{\partial t}+\bar{v}^{*} \frac{\partial \bar{\theta}}{\partial y}+\bar{w}^{*} \frac{\partial \bar{\theta}}{\partial z} \approx \bar{Q}
$$

can be rearranged to

$$
\frac{\partial \psi}{\partial y} \frac{\partial \bar{\theta}}{\partial z}-\frac{\partial \psi}{\partial z} \frac{\partial \bar{\theta}}{\partial y}=\cos (\phi) \rho_{0}\left[\bar{Q}-\frac{\partial \bar{\theta}}{\partial t}\right] .
$$

Here, $\partial y \equiv a \partial \phi, \rho_{0}$ is the log-pressure density, and the residual velocity $\left(\bar{v}, \bar{w}^{*}\right)$ is defined as in the work of Andrews et al. [1987]. Transforming the left-hand side of equation (A3) from log-pressure coordinates to $\bar{\theta}$ coordinates, i.e., $[y, z, t] \rightarrow[y, \bar{\theta}, t]$, gives

$$
\frac{\partial \psi}{\partial y} \frac{\partial \bar{\theta}}{\partial z}-\frac{\partial \psi}{\partial z} \frac{\partial \bar{\theta}}{\partial y}=\frac{\partial \bar{\theta}}{\partial z}\left(\frac{\partial \psi}{\partial y}\right)_{\bar{\theta}} .
$$

Here, we used

$$
\left(\frac{\partial}{\partial s} A\right)_{\bar{\theta}}=\left(\frac{\partial}{\partial s} A\right)_{z}+\frac{\partial A}{\partial z}\left(\frac{\partial z}{\partial s}\right)_{\bar{\theta}}
$$

where the subscripts of the brackets denote the particular vertical coordinate, $s=y$ and $A=\bar{\theta}$ or $\psi$.

By comparing equations (A4) with (A3), it follows that

$$
\cos (\phi) \rho_{0} \bar{Q}=\frac{\partial \bar{\theta}}{\partial z}\left[\left(\frac{\partial \bar{\psi}}{\partial y}\right)_{\bar{\theta}}-\cos (\phi) \rho_{0}\left(\frac{\partial z}{\partial t}\right)_{\bar{\theta}}\right]
$$

where the partial time derivative of $\bar{\theta}$ is also transformed according to equation (A5) with $s=t$. Noting that $z_{t}=-(H / p) p_{t}$ and $\bar{\theta}_{z}=-(p / H) \bar{\theta}_{p}$ where $H$ represents the scale height, $p$ the pressure and the subscripts denote partial derivatives, equation (A6) can be rewritten as

$$
\cos (\phi) \rho_{0} \bar{Q}=\frac{\partial \bar{\theta}}{\partial p}\left[-\frac{p}{H}\left(\frac{\partial \bar{\psi}}{\partial y}\right)_{\bar{\theta}}-\rho_{0} \cos (\phi)\left(\frac{\partial p}{\partial t}\right)_{\bar{\theta}}\right]
$$

Finally, approximating the zonal mean of the isentropic density as $\bar{\sigma} \approx-(1 / g)(\partial \bar{p} / \partial \bar{\theta})$ and using $p / \rho_{0}=p_{s} / \rho_{0}$ where $p_{s}$ and $\rho_{0_{s}}$ represent the constant surface pressure and surface density, it follows that

$$
\cos (\phi) \bar{\sigma} \bar{Q}=\frac{p_{s}}{H \rho_{0_{s}} g}\left(\frac{\partial \Psi}{\partial y}\right)_{\bar{\theta}}+\cos (\phi) \frac{1}{g}\left(\frac{\partial p}{\partial t}\right)_{\bar{\theta}} .
$$

Here, it is also assumed that the zonal mean net diabatic heating rate in isentropic coordinates can be approximated by $\bar{Q}$ averaged in log-pressure coordinates.

The zonal mean mass flux across an isentropic surface is therefore given by two contributions: the first term in equation (A8) represents the mass flux due to the residual velocity across the isentropic surface fixed in space, whereas the second term represents the contribution due to the up and down movement of the isentropic surface in time (compare with Figures 3 and $4 \mathrm{a}$ ). The mass flux across the upper boundary of the lowermost stratosphere was calculated according to equation (A8) using UKMO data together with radiatively derived mass streamfunction $\psi$ based on UARS constituent measurements [Rosenlof, 1995].

Acknowledgments: We wish to thank Ka Kit Tung and Hu Wang for helpful discussions about mass transport in isentropic coordinates. This research was supported by the Swiss National Research Fund (NF) and by the National Aeronautics and Space Administration (NASA), contract NAS5-26301 (UARS) and grant NAGW-662.

\section{References}

Andrews, D. G., and M. E. McIntyre, Planetary waves in horizontal and vertical shear: The generalized Eliassen-Palm relation and the mean zonal acceleration, J. Aimos. Sci., 33, 2031-2048, 1976.

Andrews. D. G.. J. R. Holton, and C. B. Leovy, Middle Atmospheric: Dynamics, Academic, 489 pp., San Diego, Calif., 1987.

Appenzeller, C., H. C. Davies, and W. A. Norton, Fragmentation of stratospheric intrusions, J. Geophys. Res., 101, 1435-1456, 1996.

Beekmann, M., et al., Stratosphere-troposphere exchange - regional and global tropopause folding occurrence, final report, Task group $3 \mathrm{~h}$, EUROTRAC, TOR, 1996. 
Brewer, A. M., Evidence for a world circulation provided by the measurements of helium and water vapor distribution in the stratosphere, Q. J. R. Meteorol. Soc., 75, 351-363, 1949.

Danielsen, E. F., Stratospheric-tropospheric exchange based upon radioactivity, ozone, and potential vorticity, J. Atmos. Sci., 25, 502$518,1968$.

Danielsen, E. F., and V. A. Mohnen, Project Dustorm report: Ozone transport, in situ measurements, and meteorological analyses of tropopause folding, J. Geophys. Res., 82, 5867-5877, 1977.

Dobson, G. M. B., Origin and distribution of polyatomic molecules in the atmosphere, Proc. R. Soc. London A, 236, 187-193, 1956

Fry, L. M., F. A. Jew, and P. K. Kuroda, On the stratospheric fallout of strontium 90: The spring peak of 1959, J. Geophys. Res., 65, 20612066, 1960.

Holton, J. R., P. H. Haynes, M. E. McIntyre, A. R. Douglass, R. B. Rood, and L. Pfister, Stratosphere-troposphere exchange, Rev, of Gesphys., 33, 403-439, 1995.

Hoskins, B. J., Towards a PV-theta view of the general circulation, Tellus, 43AB, 27-35, 1991.

Hoskins, B. J., M. E. McIntyre, and A. W. Robertson, On the use and significance of isentropic potential vorticity maps, Q.J.R. Meteorol. Soc., 111, 877-946, 1985.

Mahlman, J. D., Long-term dependence of surface fallout fluctuations upon tropopause-level cyclogenesis, Arch. Meteorol. Geophys. Bioklim., A 18, 299-311, 1969.

Murgatroyd, R. J., and A. O'Neill, Interaction between the troposphere and stratosphere, Phil. Trans. R. Soc. London A, 296, 87-102, 1980.

Olaguer, E. P., H. Yang, and K. K. Tung, A reexamination of the radiative balance of the stratosphere, J. Atmos. Sci. 49., 1242-1263, 1992.

Pawson, S., and R. S. Harwood, Monthly mean diabatic circulations in the stratosphere, Q. J. R. Meteorol. Soc., 115, 807-840, 1989.

Price, J. D., and G. Vaughan, Statistical studies of cut-off low systems, Ann. Geophys., 10. 96-102, 1992.

Reid. G. C., and K. S. Gage, On the annual variation in height of the tropical tropopause, J. Atmos. Sci., 38, 1928-1938, 1981.
Reiter, E. R., Stratospheric-tropospheric exchange processes, Rev. Geophys., 13, 459-474, 1975.

Robinson, G. D., The transport of minor atmospheric constituents between troposphere and stratosphere, Q.J.R. Meteorol. Soc., 106, 227-253, 1980.

Rosenlof, K. H., The seasonal cycle of the residual mean meridional circulation in the stratosphere, J. Geophys. Res., 100, 5173-5191, 1995.

Rosenlof, K. H., and J. R. Holton, Estimates of the stratospheric residual circulation using the downward control principle, J. Geophys. Res., $98,10,465-10,479,1993$.

Shine, K. P., Sources and sinks of zonal momentum in the middle atmosphere diagnosed using the diabatic circulation, $Q$. J. $R$. Meteorol. Soc., 115, 265-292, 1989.

Solomon, S., J. T. Kiehl, R. R. Garcia, and W. L. Grose, Tracer transport by the adiabatic circulation deduced from satellite observations. J. Atmos. Sci., 43, 1603-1617, 1986.

Staley, D. O., On the mechanism of mass and radioactivity transport from stratosphere to troposphere, J. Atmos. Sci., 19, 450-467, 1962.

Swinbank, R., and A. O'Neill, A stratosphere-troposphere data assimilation system, Mon. Weather Rev., 122, 686-702, 1994.

Tung, K. K., On the two-dimensional transport of stratospheric trace gases in isentropic coordinates, J. Atmos. Sci., 39, 2330-2355, 1982.

Yang, H., and K. K. Tung, Cross-isentropic stratosphere-troposphere exchange of mass and water vapor, J. Geophys. Res., 101, 9413. 9423, 1996.

C. Appenzeller (corresponding author) and J. R. Holton, Atmospheric Sciences, University of Washington, Box 351640, Seattle, WA 98195. (e-mail: christof@atmos.washington.edu)

K. H. Rosenlof, NOAA, University of Colorado, Boulder, CO 80302 (e-mail: krosenlof@aztec.al.bldrdoc.GOV)

(Received October 17, 1995; revised January 11, 1996; accepted February 29, 1996.) 